\title{
Sociological and Cultural Aspects of the Language Perception of the Deaf
}

\author{
Tatiana Kozlova ${ }^{1, *}$ Ludmila Dementyeva ${ }^{1}$ Elena Ilyina ${ }^{1}$ Natalya Didenko ${ }^{1}$ \\ ${ }^{1}$ Department of Humanities, Russian State Specialized Academy of Arts, Russia, Moscow \\ *Corresponding author.Email: tatiana-koz@mail.ru
}

\begin{abstract}
The article examines the basic principles of language perception, thinking and socialization of deaf people and outlines the range of problems of learning and the social role of sign language. The sociological aspect of linguistic thinking is considered in connection with the meaning of the sign language of the deaf. The authors promote the cultural-situational understanding of the discourse, based on which deaf people represent a special social group. This implies that deafness can be perceived as a special culture due to the independent language of the deaf. The article discusses the problem of the relationship between thinking and language, mental and linguistic activity, the form and content of language. The article highlights the particularities of linguistic thinking and linguistic perception of the deaf people. The authors come to the conclusion that sign language, based on visualization, presents an opportunity not only for social, but also for cultural development and understanding of the world for a deaf person.
\end{abstract}

Keywords: Deaf people, Language, Sign language, Thinking, Discourse, Language perception, Language culture.

\section{INTRODUCTION}

The so-called oralism was more widespread in the field of pedagogy in world practice. It is the method of teaching the deaf oral speech, which was consolidated at the Milan conference on the education of the deaf in 1880. But oralism is not just a tracing language, it is a method of communication in which it is unacceptable to use other means of information transmission, except speech. It led to discrimination of sign language. This method is perceived as a means of rehabilitation, and it is relevant in attitudes towards deafness as a pathology that needs to be corrected.

It is noted that the change towards the deaf in social terms occurs in the 70s of the twentieth century. "Deafness in this case is viewed not as a pathology of the living organism, a defect, a permanently established reality, but as a social construct, the content of which depends on the values and norms of a particular society." [1]
But the deaf can be perceived through a cultural model due to sign language. The interest of researchers in this language arose in the middle of the twentieth century. Linguists began studying sign language as an independent language. The most topical researches for us are those in the field of sociolinguistics. The question about social role of sign language arose at the beginning of its linguistic study. Such issues as the language functions in society, attitude to language and language policy are studied by sociolinguistics. Their study in connection with sign language is especially important as there are the problems of education, the relationship between the deaf and the hearing, the struggle of the deaf for their rights, first of all, the right to the recognition of sign language.

\section{SOCIOLOGICAL ASPECT OF THE LINGUISTIC CULTURE OF THE DEAF}

The first world conference of the deaf, dedicated to the language, culture and history of deaf people, took place in 1989. It was a sociolinguistic event, the main idea of which was 
the proposal for a cultural identity of the deaf, which is closely related to sign language.

At present, deaf communities are very active, they have their own language policy and they are engaged in the empowerment of the deaf. The rights and abilities of the deaf are primarily related to the use of sign language, solution of education problems and the choice of communication means, including the participation of sign language interpreters.

Regional and social differences, bilingualism, language contacts, preservation and choice of language, language relations, language policy and planning, and language and social interaction are important problems of the deaf community studied by modern sociolinguistics. Today researchers identify the most topical questions to study:

- the connection between the spoken language of the majority community and sign language, especially in educational institutions;

- limited knowledge of the linguistic structure of sign language;

- doubts about the real status of sign language as a "real language";

- application of sociolinguistic models of spoken language for linguistic situations. [2]

Deaf communities have their own culture specifications, based on sign language.

In social terms, the communities of the deaf are reserved and first of all this is due to the peculiarity of linguistic communication. They have their own associations, theaters, churches and cultural events. Russian sociologists note that deaf people prefer activities that are organized specifically for the deaf, despite the availability of other activities. [3] American researchers of the social aspect of teaching the deaf in specialized schools note that through communication with each other deaf people develop a sense of identity with a group of deaf people and acquire social relationships that distinguish them into a separate group. This is how the subculture of the deaf is formed, united by social, cultural and linguistic identity.

Deaf communities consider deafness as a special culture, primarily linguistic. Their isolation also creates a special social stratum of society. They have an idea that deafness is like ethnicity. Since this position is not always supported by society, deaf people can be in social confrontation.
This affects many aspects of life, and problems are found in the field of education. And there is no consensus among the deaf about the use of language or attitude towards bilingualism.

Vygotsky notes that compensation for a defect in a child is associated with adaptation to the social environment. While growing up the child enters the environment through natural and cultural development. Both development plans form a single series of socio-biological personality formation. The development of speech is an example of the union of natural and cultural development paths. For a deaf child who has difficulty in speaking, it is necessary to create a cultural form, such as sign language. [4]

Deaf people usually learn their native language (not sign language) slower than their hearing peers. They have difficulties in writing, as if they don't write in their native language. The authors of articles about the deaf, as well as our observation, give evidence of it. In colloquial speech, deaf people use sign language, mastering it together with their peers. This is especially well seen in families with deaf parents.

According to E. Sapir, language is a "powerful factor of socialization", "a guide to social reality", and speech can be called a symbol of "social solidarity" of those who speak the same language. [5]

Thus, we can talk about the connection between language and sociocultural processes. In modern linguistic theories, this issue is considered within the framework of discoursology.

The cultural-situational understanding of discourse, which is relevant for this study, interprets it as a logical text "taken in the event aspect" in connection with socio-cultural, psychological, extralinguistic and other factors. Speech is viewed as a social action and discourse as "speech immersed in life". [6]

Discourse is called "the central moment of human life in language, linguistic existence", representing a part of human experience. This experience includes ethnic and cultural models of behavior that are expressed in speech and language.

Discourse analysis is an interdisciplinary area of research, which is at the intersection of linguistics, sociology, psychology, semiotics, philosophy. There are various positions from which discourse can be studied. The most relevant idea for us is that 
communicative situations should be considered in a cultural context.

The so-called linguistic behavior is studied within the framework of discourse. Van Dijk interprets discourse as a communicative event closely related to social and cultural ideology. The discourse reproduces macro-social phenomena such as ideology and culture. Discourse as a concept can be used in relation to a historical period, a social community, or a particular culture. In this basis, the concept of "discourse of the deaf" can be used by analogy. Deaf people can represent a special social group, and their culture is built primarily on the language.

Van Dijk pays great attention to the study of ideology in the framework of discourse. He highlights such aspects of research as the relationship between ideologies and social structures, ideologies and values, ideologies and social practices in general.

Van Dijk makes a conclusion that the main cognitive function of ideologies is the organization of the group's social presentations. Thus, they control social and personal opinions and, ultimately, social practices and discourse.

Van Dijk considers it important to explore understanding, communication and interaction based on "mental frames" such as language, way of thinking and concepts within a social group. $[6,10]$

\section{THE RELATIONSHIP BETWEEN THINKING AND LANGUAGE}

The relationship among thinking, speech and language is a subject of study by psychologists, linguists and philosophers.

E. Sapir researched changes in language in time and space and how language relates to historical processes, culture, art and intellection.

It leads us to regard language as an instrument that can be used in all conditions. Speech reflects the inner world and is parallel to consciousness in various conditions, in mental states that are caused by images, while focusing attention on abstract meanings and relationships between them, namely, reasoning. In a language, its external form is constant, and the internal content, mental component and intensity depend on the circumstances, orientation and mental activity and are closely related to general mental development. Sapir connects mentality with the highest potential content of speech, which can be achieved, realizing that each element of speech has conceptual significance.

According to E. Sapir, people are under considerable influence of the real language, which is a means of communication for a certain group, as their "real world" is unconsciously built on the linguistic norms of this group. [7]

Developing the idea of Sapir, B. Wharf conducts a comparative analysis of the European languages and the Hopi language in order to prove the connection between language, thinking and behavior. He notes that people in different situations behave according to how they are spoken about. Analysis of Hopi behavior allows Whorf to draw parallels between the peculiarities of language formulation and lifestyle (cooking, ceremonies, etc.).

Theories of L.S. Vygotsky are close to the views of Sapir and Whorf in terms of proving the influence of language on cognition.

Both thinking and speech develop in their own way, despite the seeming interconnection. L.S. Vygotsky points out that the unit, which contains the properties of speech and thinking, lies in the meaning of the word. And each word is a generalization, its meaning is "a generalized reflection of reality". [8] The act of thinking is associated with a word, its meaning, which can be considered as a phenomenon of the area of thinking and the area of speech. Word is a unit of verbal thinking.

According to J. Piaget, mental activity itself is not logical. Logical activity is a search for truth, finding a solution depends on imagination, but the need for logical activity arises quite late. A thought arises before the search for truth. [9] It might be explained by the fact that a child's thought is associated with the satisfaction of his needs, which at an early stage are limited by a game, "mirage imagination", which allows a child to wishful thinking.

Developing this idea of J. Piaget, Vygotsky comes to the conclusion that thinking and imagination in their development are opposites, but their unity lies in generalization that a person forms. According to Vygotsky, the study of realistic and autistic thinking is facilitated by the possible unity of such opposites as concept and fantasy. [9]

Internal speech, according to Vygotsky, develops in the process of accumulation of functional changes, when it is separated from the 
child's external speech together with the differentiation of the initial egocentric and social speech and speech structures become structures of thinking.

According to Vygotsky, the word and its meaning is a hidden generalization. "It is easy to see that generalization is an extraordinary verbal act of thought, reflecting reality in a completely different way than it is reflected in immediate feelings and perception." The existence of the socalled "dialectical leap" between feelings and thoughts means that "thinking reflects reality in consciousness in a qualitatively different way than direct sensation. Apparently, there are some reasons to assume that this qualitative difference of the unit is a generalized reflection of reality." [8]

Piaget notes that the essence of language of children under seven years old is gestures, facial expressions and words equally. At the same time, Piaget separates words from gestures and facial expressions. Since children do not understand language without action, then facial expressions and gestures represent the beginning of action for them.

During learning, children get acquainted with the words, names of objects. Meeting a new object they learn its name. The word is more a feature for a child than a symbol. A child "masters the external structure: a word is a thing that afterwards becomes a symbolic structure". [8]

Getting acquainted with real objects, children first draw objects then give names to them. So the visual component develops earlier than the verbal one. For children things are reality that they face in the cognitive process. Vygotsky says that the "feature" of a thing is its name which can be separated from the thing itself since it's possible to see things and not to hear their name or not to see a thing which name is known. [8]

In linguistic studies the question of the relationship between language and thinking is often raised. It is of interest in connection with the language thinking of deaf people. L. Wittgenstein's Logical-philosophical Tractate presents the logical model "language — logic — reality" which clarifies the informative and cognitive possibilities of comprehending the world through language. This is not about thinking as such but about the expression of thought.

"3.1. A thought in a sentence is a perceived expression. 3.11. We use sensuously perceived signs (sound or written, etc.) in sentences as a projection of a possible state of things. The method of projection is thinking of the meaning of a sentence." [10]

Linguistic thinking and linguistic perception of the deaf have their own differences. In sign language sounds are replaced by visual representation. From the point of view of sensory perception we deal only with the visual perception. But for the deaf there is a difference in understanding the sentence as an image or model of reality which is expressed in writing or with the help of a gesture. "Propositional signs" that have the same semantic meaning are perceived by the deaf in different ways, that is, they are different signs. The content of a propositional sign becomes clear if it is presented not in writing, but consisting of imaginary objects. "The spatial arrangement of these things will then express the meaning of the sentence". [10] This is fully implemented in sign language.

Wittgenstein calls each part of a sentence a symbol that characterizes its meaning. In his opinion, "the expression characterizes the form and content", and the sign is "the sensuously perceptible part of the symbol". Written and sound forms have a common sign, but are expressed in different ways, that is, verbal and visual signs have two ways of perception. The sentence can be read or heard and perceived (understood) by recipients from their personal experience. Sign language simplifies the form of perception since the sound component is replaced by a visual (imaginary) one, but another visual (written) component becomes more difficult to perceive (understand). "The specific method of symbolization may be irrelevant, but it is always essential that there is a possible method of symbolization". [10]

Wittgenstein calls the sentence the image of reality, as well as the model of reality as we see it. At the same time a sentence written or printed on paper cannot be called the "image of reality" which it represents. "But at first glance the notes also do not seem to be the image of music, and our phonetic signs (letters) do not seem to be the image of our oral speech. And yet these symbols, even in the usual sense of the word, turn out to be images of what they represent." [10] In sign language, "phonetic signs" are replaced by visual signs that are an image of reality.

Speech is based not only on associations, but is connected with higher intellectual processes, where the relationship between a sign and a structure of an intellectual operation is important. To create the 
process of concept formation it's necessary to arise such a task, and linking words with objects and learning them by heart does not lead to the formation of understanding.

Researchers note that a child's thinking largely comes from the relationship between him or her and the surrounding social environment, on which the structure of a person's thinking depends. As children get older and communicate with each other and the adults around them the rules of cooperation start developing that shape the way of thinking. [8]

The language reflects the idea of social processes and characteristics. As Sapir says, people are more obsessed with their language than the material or social world.

"Each language itself is a kind of collective art of expression. It contains a complex of special aesthetic factors - phonetic, rhythmic, symbolic, morphological, which do not completely coincide with what presents in any other language ". [5]

For I.G. Herder, who explores the history of the origin of language, the language is a form of human thoughts; it is not just a means for creating literature. Thinking comes with the help of words, therefore the study of the etymology of the word promotes better understanding of human thinking. [11]

\section{THE RELATIONSHIP BETWEEN LANGUAGE AND CULTURE}

These speculations lead us to the idea of the meaning of form and content. Language cannot be regarded only as a form through which certain content can be expressed. It is associated with thinking, the development of human society, the spirit of the people.

According to Sapir, "we can regard language as a symbolic guide to understanding culture." [5]

Sapir defines culture as what society does and thinks, and he defines language as how people think. Various social factors, including language, form a person's thinking and social environment.

Since the deaf culture carriers are closely related to the specific environment in which they develop, they belong to a special system of worldview. Deaf people cannot be considered as carriers of two cultures, but at the same time, being representatives of a particular social culture, they represent this special culture. This is very similar to what happens in the language of the deaf. Deaf people are not considered bilingual, but they use two types of language - sign spoken and sign tracing languages. And the sign spoken language can act as compensation for a person with loss of hearing.

According to Chomsky, there is a mismatch between knowledge and experience, and between grammar and the lack of data on which it is built. Chomsky concludes that there is a "natural structure" that compensates this mismatch. This means that the grammar is already installed in the human brain and is waiting for actualization. [12] It means that the ability to master any language, including sign language, is inherent in a person from birth.

Thus, we can say that the concept of grammar and "internal grammar" is also applicable to sign language.

O. Sachs notes that sign language is of particular interest from the point of view of the development of the so-called "internal speech" about which Vygotsky wrote. "Internal speech" is an independent function, the generation of thoughts, thinking with meanings. Speech develops thinking, the language of communication helps to create "internal speech", that is, during communication, we move from external to internal speech. According to O. Sachs, the real identity of a person, consciousness and intellect are closely related to inner speech. With the help of inner speech, concepts are formed, ideas are developed, understanding occurs. Sign speech is close to inner speech and is a very special phenomenon. [1]

This definition is very close to the idea of Wilhelm von Humboldt about the linguistic worldview. Humboldt discovers the initial form of uniting people into a "linguistic community", which he understands as a necessary condition for the formation of a personality, which is closely related to the development of linguistic culture.

Despite the fact that in the biological sense, language and thinking have different origins, personality development is possible only with the help of language. Historically, researching and exploring the surrounding world was possible even before the origin of language, but there were visual means of communication, which later developed into linguistic grammatical constructions. Thus, visuality is the primary means for going beyond narrow thinking and a closed world. In this sense, the sign language, built on visuality, represents an 
opportunity for the development of world outlook and worldview.

\section{CONCLUSION}

Despite the fact that in the biological sense, language and thinking have different origins, personality development is possible only with the help of language. Historically, researching and exploring the surrounding world was possible even before the origin of language, but there were visual means of communication, which later developed into linguistic grammatical constructions. Thus, visuality is the primary means for going beyond narrow thinking and a closed world. In this sense, the sign language, built on visuality, represents an opportunity for the development of world outlook and worldview.

\section{AUTHORS' CONTRIBUTIONS}

The main idea of the article belongs to $\mathrm{T}$. Kozlova and N. Didenko.

Aspects related to the problems of deaf people were developed by T. Kozlova and E. Ilyina.

Worked on the text - T. Kozlova and L. Dementyeva.

General management was carried out by Didenko.

\section{REFERENCES}

[1] Bolshakov N.V. From deviation to identity: transformation of scientific approaches to understanding deafness // Journal of Sociology and Social Anthropology. 2016. Volume XIX. № 2 (85). P. 164.

[2] The Sociolinguistics of Sign Languages. Edited by Ceil Lucas. Cambridge University press, 2001. P. 4.

[3] Bolshakov N.V. Possibilities of using the strategy of mixing methods in the study of the community of the deaf and hearing impaired. // Bulletin of Tomsk State University. 2017 №38. P. 154-165.

[4] Vygotsky L.S. Fundamentals of defectology. M., 1983. P. 22,23.
[5] Sapir E. Selected works on linguistics and cultural studies. M., 1993. P. 230,231.

[6] Karasik V.I. Discourseology as a direction of communicative linguistics // Actual problems of philology and pedagogical linguistics, 2016, № 1. P. 17-34.

[7] Whorf B. The relation of norms of behavior and thinking to language // New in linguistics. Issue. 1. - M., 1960. P. 135-169.

[8] Vygotsky L.S. Thinking and speaking. M., 1999. P. 14.

[9] Piaget J. Speech and thinking of a child. M., 1932. P. 372.

[10] Wittgenstein L. Logical-Philosophical Treatise. DOI: http://www.philosophy.ru/library/witt/01/01.ht ml. P. 6.

[11] Herder I.G. A treatise on the origin of language. M., 2007.

[12] Sachs O. Visible Voices. M., 2014. P. 89. 